\title{
Treatment of Wilson's Disease With Zinc. XVII: Treatment During Pregnancy
}

\author{
George J. Brewer, ${ }^{1}$ Virginia D. Johnson,${ }^{2}$ Robert D. Dick, ${ }^{2}$ Peter Hedera, ${ }^{3}$ John K. Fink, ${ }^{3}$ and Karen J. Kluin ${ }^{4}$
}

SEE EDITORIAL ON PAGE 531

Therapy of Wilson's disease continues to evolve. In 1997, zinc acetate was added to the list of drugs approved by the Food and Drug Administration, which includes penicillamine and trientine. The mechanism of zinc's anticopper action is unique. It induces intestinal cell metallothionein, which binds copper and prevents its transfer into blood. As intestinal cells die and slough, the contained copper is eliminated in the stool. Thus, zinc prevents the intestinal absorption of copper. It is universally agreed that pregnant Wilson's disease patients should remain on anticopper therapy during pregnancy. There are numerous reports of such patients stopping penicillamine therapy to protect their fetus from teratogenicity, only to undergo serious deterioration and even death from renewed copper toxicity. Penicillamine and trientine have teratogenic effects in animals, and penicillamine has known teratogenic effects in humans. In this report we discuss the results of 26 pregnancies in 19 women who were on zinc therapy throughout their pregnancy. The evidence is good that zinc protects the health of the mother during pregnancy. Fetal outcomes were generally quite good, although one baby had a surgically correctable heart defect and one had microcephaly. (HePATOLOGY 2000;31:364-370.)

Wilson's disease is a rare autosomal recessive disorder in which copper accumulates, eventually leading to liver disease, and in some patients neurological disease manifesting as a movement disorder, often complicated by behavioral disturbances. ${ }^{1}$ Patients generally become ill in their late teenage years or early twenties, although age of onset can be quite broad, ranging from early childhood into the fifties. After diagnosis of an index case, siblings are screened, with $25 \%$, on average, being affected but in a "presymptomatic" state.

From the ${ }^{1}$ Departments of Human Genetics and Internal Medicine; ${ }^{2}$ Department of Human Genetics; ${ }^{3}$ Department of N eurology; the ${ }^{4}$ Department of N eurology, Division of Speech Pathology, and Department of Physical Medicine and Rehabilitation, University of Michigan Medical School, Ann Arbor, MI.

Received July 19, 1999; accepted N ovember 30, 1999.

Supported in part by FDA grants FD-R-000179 and FD-U-000505 from the Orphan Products Office. The assistance and support of the Clinical Research Center of the University of Michigan Hospitals was supported in part by NIH grant M 01-RR00042. J.K.F. is supported by grants from the National Institutes of Health (1R01NS36177-01A10, 1R01N S33645-01, and 1R01N S38713-01) and a Veteran's Affairs Merit Review Award.

Address reprint requests to: George J. Brewer, M.D., The University of Michigan Medical School, Department of Human Genetics, 4708 Medical Science II, Ann Arbor, Michigan 48109-0618. E-mail: brewergj@umich.edu; fax: 734-615-2048.

Copyright (c) 2000 by the American Association for the Study of Liver Diseases.

0270-9139/00/3102-0017\$3.00/0
The disease is caused by mutation in a gene called ATP7B producing a copper-binding adenosine triphosphatase, expressed in the liver and a few other tissues. ${ }^{2-4}$ Homozygosity or compound heterozygosity for defects in this gene lead to a failure of the liver to excrete copper in the bile destined for loss in the stool. ${ }^{5-8}$ This excretion is necessary to maintain a neutral copper balance. An epistatic effect of this genetic defect is usually a low blood ceruloplasmin. Ceruloplasmin is a copper-containing molecule synthesized in large amounts by the liver and may be the copper-packaging, proteaseresistant molecule that is excreted into the bile to get rid of excess copper via the stool. ${ }^{9}$ Thus, if ATP7B results in an immature ceruloplasmin (for example without copper), the genetic defect in Wilson's disease could result in both a failure of ceruloplasmin secretion into blood and excretion into bile.

Wilson's disease is effectively treated by three U.S. Food and Drug Administration-approved anticopper agents, which include zinc, ${ }^{1}$ penicillamine, ${ }^{10}$ and trientine. ${ }^{11}$ In January, 1997 the Food and Drug Administration approved zinc for the maintenance therapy of Wilson's disease, based on our work in developing this therapy. ${ }^{1,12-28}$ Schouwink $^{29}$ and Hoogenraad et al.30-32 have also used zinc to treat Wilson's disease. Because zinc is essentially nontoxic, and the other two agents have toxic side-effects, in our opinion zinc is now the preferred maintenance therapy for Wilson's disease.

There are no contraindications to pregnancy in Wilson's disease during maintenance therapy, with the exception of the presence of severe liver disease. However, it is very important that treatment of Wilson's disease with anticopper agents continues during pregnancy.1,27,33 In the past, a number of pregnant women have stopped penicillamine during pregnancy, knowing it is teratogenic. There are numerous reports of such women suffering from severe regression of their disease, often ending in death. ${ }^{33-36}$

Of the 3 anticopper agents available for treatment during pregnancy, we favor zinc. Penicillamine is teratogenic in animals ${ }^{37}$ and produces a teratogenic syndrome in human babies. ${ }^{38-40}$ Trientine is teratogenic in animal studies. ${ }^{41,42} \mathrm{Zinc}$ has been studied for teratogenicity and is not teratogenic. ${ }^{43}$ This report discusses our experience in treating women with Wilson's disease with zinc during pregnancy.

\section{MATERIALS AND METHODS}

The pregnant patients primarily came from the large group of Wilson's disease patients we have been following for the development of zinc therapy. ${ }^{27}$ Every patient from this group who became pregnant was included in the study. In addition, there were 2 patients not from our group of patients who contacted us to go on zinc during pregnancy. Through their physicians we managed zinc therapy in these two using an "off-site protocol."

The diagnosis of Wilson's disease was established by previously 
published methods. ${ }^{12-16}$ Table 1 provides basic data on the 19 women who were involved in the 26 live birth pregnancies. Two of the women were Hispanic and accounted for 4 pregnancies. One woman was Asian, 1 was East Indian, and the rest were Caucasian (Table 1). Seven of the 19 women, accounting for 10 pregnancies, were classified as presymptomatic, meaning that they were diagnosed before presenting clinically. Eight of the patients had presented neurologically, and 3 had presented with liver disease (Table $1)$. We do not know the clinical classification of 1 off-site patient (patient 314).

Many of the patients had been on zinc for a long time before the pregnancy (Table 1$)$. In 11 pregnancies, prior zinc treatment was over 5 years. In 18 of the pregnancies, the women were on $50 \mathrm{mg}$ of zinc 3 (or 2) times a day at the start, whereas 6 were on $25 \mathrm{mg}$ of zinc 3 (or 2) times a day. Two patients were on penicillamine and were switched to zinc during the second month of pregnancy (Table 1).

The 25- and 50-mg zinc acetate capsules used in this study were compliments of Gate Pharmaceutical Co. (M ontgomeryville, PA), whose product is named Galzin. U rine, plasma, and liver copper and zinc concentrations were measured by previously published methods. ${ }^{12-16}$ The protocol and consent procedures used in this study were approved by the Institutional Review Board of the University of Michigan. Each patient in this study was fully informed about the project and gave written consent.

Liver function tests on blood samples were performed by standard methods in the clinical biochemistry laboratory of the University of Michigan Hospital. Quantitative neurological and speech scores were determined by previously published methods. ${ }^{44}$

\section{RESULTS}

The primary monitoring tool of copper status we use while patients are on zinc therapy is 24-hour urine copper (Table
2). This has the advantage that it can be monitored fairly frequently, even at long distance, because a mail-in system is used, and in our experience, 24-hour urine copper is the single best monitoring tool for zinc therapy. The nonceruloplasmin plasma copper can also be used for monitoring if the patients are available for taking blood samples, but in this study, they were not available. Table 2 shows first the urine copper that was done closest to the time before pregnancy began. Based on experience, 24-hour urine copper values of $0.125 \mathrm{mg}$ or less indicate adequate control of copper status ( 0.02 to $0.05 \mathrm{mg}$ is the normal range). It can be seen from the second column of Table 2 that most of our patients had good control of copper before pregnancy, although in some cases the closest study was many months before pregnancy (column 3). An exception is patient 38. We had actually discharged her from our patient study group because of noncompliance and her habit of taking mineral supplements that included copper. We did provide her with zinc to take during pregnancy, and she agreed to provide information about the pregnancy outcome. As can be seen from Table 2, we were unable to obtain urine copper samples during or after pregnancy in patient 38 , although we did get a verbal report from her obstetrician that she delivered a healthy full-term baby. The 2 patients at the bottom of Table 2 are "off-site" patients, that is patients who did not come to the University of Michigan to visit us. Both were on penicillamine, became pregnant, and they and their doctors requested our help in getting them on zinc therapy during pregnancy. We supplied zinc for these patients during pregnancy. Patient

TABle 1. Demographic Summary of the 26 Live-Birth Pregnancies in 19 Women

\begin{tabular}{|c|c|c|c|c|c|c|c|c|c|}
\hline $\begin{array}{l}\text { Patient } \\
\text { No. }\end{array}$ & $\begin{array}{l}\text { Ethnic } \\
\text { Origin* }\end{array}$ & $\begin{array}{c}\text { Clinical } \\
\text { Presentation } \dagger\end{array}$ & $\begin{array}{c}\text { Age at } \\
\text { Diagnosis } \\
\text { (Yrs) }\end{array}$ & $\begin{array}{c}\text { Age at Start } \\
\text { of Zinc Therapy }\end{array}$ & $\begin{array}{c}\text { Present Age } \\
\text { (Yrs) }\end{array}$ & $\begin{array}{c}\text { Pregnancy } \\
\text { No. }\end{array}$ & $\begin{array}{l}\text { Age at Birth } \\
\text { of } C \text { hild }\end{array}$ & $\begin{array}{l}\text { Years of Zinc } \\
\text { Therapy at } \\
\text { Birth of C hild }\end{array}$ & $\begin{array}{l}\text { Dose of Zinc } \\
\text { at Start of } \\
\text { Pregnancy }\end{array}$ \\
\hline 27 & $\mathrm{H}$ & $P$ & 19 & 19 & 33 & 1 & 29.0 & 10.1 & $50 \times 3$ \\
\hline \multirow[t]{2}{*}{32} & $\mathrm{H}$ & $P$ & 23 & 23 & 37 & 1 & 25.2 & 1.8 & $50 \times 3$ \\
\hline & & & & & & 2 & 25.8 & 2.4 & $50 \times 3$ \\
\hline 34 & C & $\mathrm{N}$ & 20 & 29 & 42 & 1 & 35.8 & 6.7 & $50 \times 3$ \\
\hline \multirow[t]{2}{*}{45} & C & $P$ & 26 & 27 & 39 & 1 & 28.7 & 1.5 & $50 \times 3$ \\
\hline & & & & & & 2 & 31.5 & 4.4 & $50 \times 2$ \\
\hline \multirow[t]{2}{*}{49} & C & $\mathrm{N}$ & 17 & 24 & 36 & 1 & 27.0 & 2.5 & $50 \times 3$ \\
\hline & & & & & & 2 & 31.7 & 7.3 & $25 \times 3$ \\
\hline \multirow[t]{2}{*}{52} & C & $\mathrm{N}$ & 24 & 27 & 37 & 1 & 29.2 & 2.6 & $50 \times 3$ \\
\hline & & & & & & 2 & 30.4 & 3.9 & $25 \times 3$ \\
\hline \multirow[t]{2}{*}{113} & C & $\mathrm{H}$ & 20 & 26 & 32 & 1 & 31.4 & 5.2 & $25 \times 3$ \\
\hline & & & & & & 2 & 33.0 & 6.2 & $25 \times 3$ \\
\hline 130 & C & $P$ & 28 & 32 & 38 & 1 & 37.8 & 5.3 & $25 \times 2$ \\
\hline 172 & C & $\mathrm{N}$ & 20 & 20 & 24 & 1 & 24.2 & 4.0 & $50 \times 3$ \\
\hline 173 & C & $\mathrm{N}$ & 21 & 21 & 25 & 1 & 25.7 & 4.0 & $50 \times 3$ \\
\hline 180 & C & $\mathrm{N}$ & 25 & 29 & 32 & 1 & 33.2 & 3.0 & $50 \times 3$ \\
\hline 204 & El & $P$ & 27 & 28 & 31 & 1 & 31.2 & 3.5 & $50 \times 3$ \\
\hline 312 & $\mathrm{C}$ & $P$ & 10 & 29 & 33 & 1 & 30.1 & 0.7 & Pen \\
\hline 314 & A & & & & & 1 & & & Pen \\
\hline
\end{tabular}

Abbreviation: Pen, penicillamine.

$* H$, Hispanic; C, Caucasian; A, Asian; El, East Indian.

$\dagger P$, presymptomatic; $N$, neurological; $H$, hepatic. 
Table 2. Urine Copper Data Prior to, During, and After Pregnancy (in $\mathrm{mg} / 24$ hours)

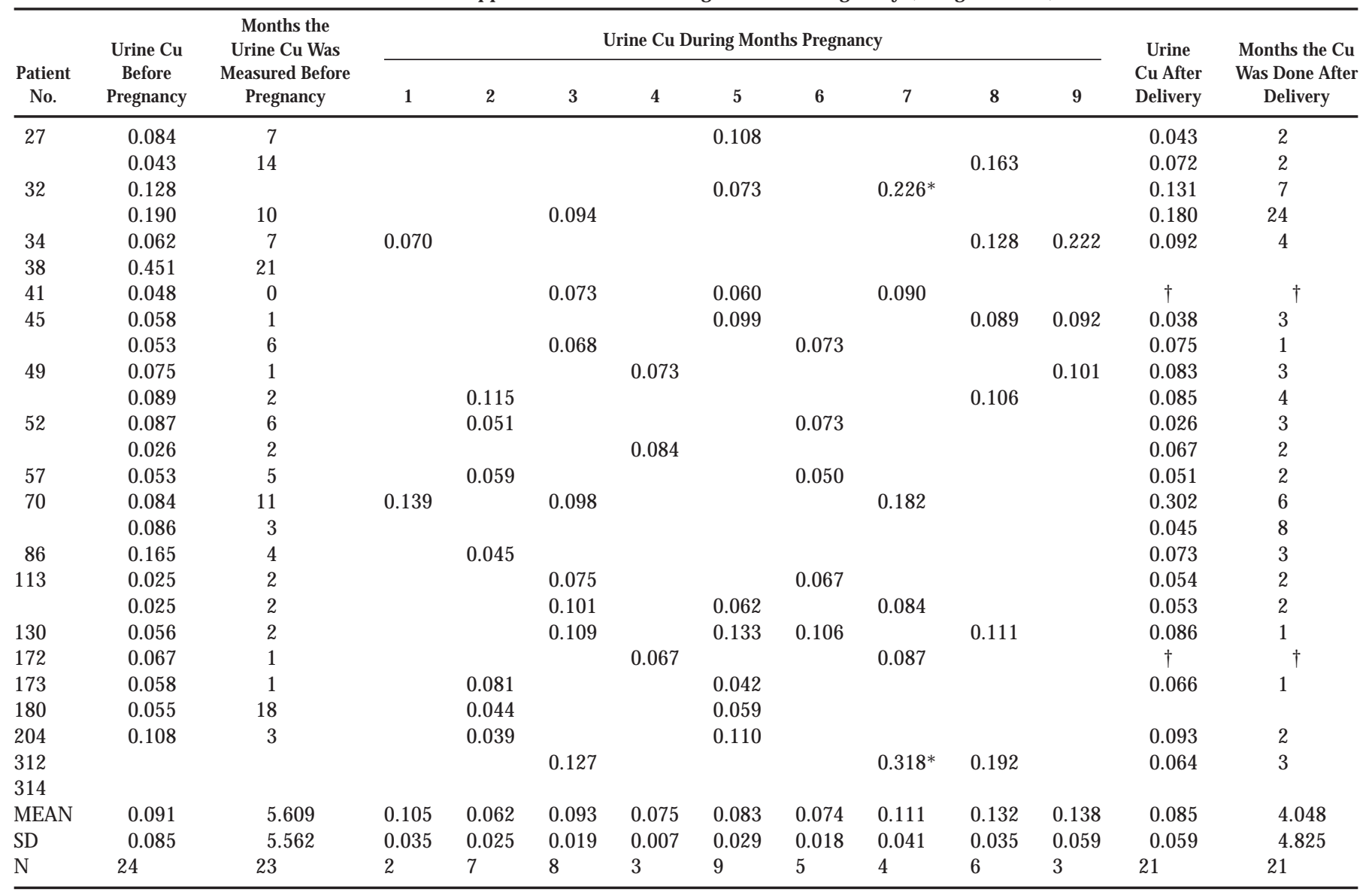

$*$ Increased dose to $50 \times 3$.

$\dagger \mathrm{N}$ ewborn at time of submission, data not yet available.

312 provided interim and postpregnancy urine samples, whereas patient 314 did not.

To evaluate the control of copper status during pregnancy in these patients, it is useful to use Tables 2 and 3 together. Table 3 provides zinc dose information. Our standard recommended adult maintenance dose is $50 \mathrm{mg}$ of zinc 3 times daily $(50 \times 3)$. In many cases we tried to use a dose of $25 \mathrm{mg}$ of zinc 3 times daily $(25 \times 3)$ during pregnancy, with the rationale that that was the minimally effective adult dose, ${ }^{20,27}$ and carried, theoretically, the least risk to the fetus. The following patients were treated through more than half of their pregnancy with this dose or lower (Table 3): patient 27, pregnancies 1 and 2; patient 32, pregnancy 2; patients 34 and 41; patient 45, pregnancies 1 and 2; patient 49, pregnancy 1; patient 52, pregnancies 1 and 2; patient 57; patient 113, pregnancies 1 and 2; patient 130,312, and 314. This is a total of 16 pregnancies. Examining the urine copper data of Table 2 in these patients, we see that the following patients remained well controlled on this dose: patient 27, pregnancy 1 ; patient 32 , pregnancy 2 ; patient 41 ; patient 45 , both pregnancies; patient 49; patient 52, both pregnancies; patient 57; patient 113, both pregnancies; and patient 130 , for a total of 12 of the 15 on whom we have data (no data on patient 314). Patient 27 during pregnancy 2 had a urine copper of $0.163 \mathrm{mg}$ in month 8, which was higher than we like to see. However, her urine zinc value was $3.5 \mathrm{mg} / 24$ hours (we view any level over $2.0 \mathrm{mg}$ as indicating adequate zinc therapy and compliance), and we did not change her dose. Patient 312 had a urine copper of $0.318 \mathrm{mg}$ at month 7 , and although her urine zinc was $4.1 \mathrm{mg}$, we increased her zinc dose. Other data pertinent to using a lower zinc dose range during pregnancy included patient 32 , pregnancy 1 . We decreased her dose to $25 \times 2$ at month 3 , and had to increase it to $50 \times 3$ at month 7 when her urine copper came back at $0.226 \mathrm{mg}$ in association with an inadequate urine zinc of $0.8 \mathrm{mg}$. Patient 34 went on a dose of $25 \times 3$ at month 2 , and at month 9 showed a urine copper of $0.222 \mathrm{mg}$, well above desired limits, but her urine zinc was $4.2 \mathrm{mg}$, and we did not increase the dose. The change in dose in patient 49 , pregnancy 2 , had nothing to do with a change in copper status. In summary, in 4 of 16 cases (where we have urine copper data) on lower doses of zinc, urine copper values were higher than desired, and in 2 patients we felt we had to increase the dose to $50 \times 3$ during pregnancy to regain control of copper status (patients 312 and 32). The increase in urine copper in patient 32 appears to be caused by noncompliance, while in patient 312, compliance, based on urine zinc at the time of sample submission, seems to have been adequate. However, the margin for error with noncompliance is much smaller on a dose of $25 \times 3$ than it is on $50 \times 3$.

Patients primarily on a dose of $50 \times 3$ during pregnancy included patient 70 , both pregnancies; and patients 86,172 , 173, 180, and 204 (we don't include 38 because of lack of data). These patients did well in terms of copper control 
TABLE 3. Zinc Dose Data Before and During Pregnancy

\begin{tabular}{|c|c|c|c|c|c|c|c|c|c|c|c|}
\hline \multirow{2}{*}{$\begin{array}{l}\text { Patient } \\
\text { No. }\end{array}$} & \multirow{2}{*}{$\begin{array}{l}\text { Zinc Dose Before } \\
\text { Pregnancy }\end{array}$} & \multicolumn{9}{|c|}{ Months of Pregnancy } & \multirow{2}{*}{$\begin{array}{l}\text { Zinc Dose at End } \\
\text { of Pregnancy }\end{array}$} \\
\hline & & 1 & 2 & 3 & 4 & 5 & 6 & 7 & 8 & 9 & \\
\hline \multirow[t]{2}{*}{27} & $50 \times 3$ & $\rightarrow$ & $\rightarrow$ & $25 \times 3$ & $\rightarrow$ & $\rightarrow$ & $\rightarrow$ & $\rightarrow$ & $\rightarrow$ & $\rightarrow$ & $25 \times 3$ \\
\hline & $50 \times 3$ & $25 \times 3$ & $\longrightarrow$ & $\rightarrow$ & $\longrightarrow$ & $\rightarrow$ & $\longrightarrow$ & $\longrightarrow$ & $\longrightarrow$ & $\rightarrow$ & $25 \times 3$ \\
\hline \multirow[t]{2}{*}{32} & $50 \times 3$ & $\rightarrow$ & $\longrightarrow$ & $25 \times 2$ & $\longrightarrow$ & $\longrightarrow$ & $\longrightarrow$ & $50 \times 3$ & $\longrightarrow$ & $\rightarrow$ & $50 \times 3$ \\
\hline & $50 \times 3$ & $\rightarrow$ & $\rightarrow$ & $25 \times 3$ & $\rightarrow$ & $\rightarrow$ & $\rightarrow$ & $\rightarrow$ & $\rightarrow$ & $\rightarrow$ & $25 \times 3$ \\
\hline 34 & $50 \times 3$ & $\rightarrow$ & $25 \times 3$ & $\rightarrow$ & $\longrightarrow$ & $\longrightarrow$ & $\longrightarrow$ & $\longrightarrow$ & $\longrightarrow$ & $\rightarrow$ & $25 \times 3$ \\
\hline 38 & $50 \times 3$ & $\rightarrow$ & $\rightarrow$ & $\longrightarrow$ & $\longrightarrow$ & $\longrightarrow$ & $50 \times 4$ & $\longrightarrow$ & $\longrightarrow$ & $\rightarrow$ & $50 \times 4$ \\
\hline 41 & $25 \times 3$ & $\rightarrow$ & $\longrightarrow$ & $\longrightarrow$ & $\longrightarrow$ & $\rightarrow$ & $\longrightarrow$ & $\rightarrow$ & $\longrightarrow$ & $\rightarrow$ & $25 \times 3$ \\
\hline \multirow[t]{2}{*}{45} & $50 \times 3$ & $25 \times 2$ & $\longrightarrow$ & $\longrightarrow$ & $\longrightarrow$ & $\longrightarrow$ & $\rightarrow$ & $\longrightarrow$ & $\longrightarrow$ & $\rightarrow$ & $25 \times 2$ \\
\hline & $50 \times 2$ & $25 \times 3$ & $\rightarrow$ & $\longrightarrow$ & $\longrightarrow$ & $\rightarrow$ & $\rightarrow$ & $\rightarrow$ & $\rightarrow$ & $\rightarrow$ & $25 \times 3$ \\
\hline \multirow[t]{3}{*}{49} & $50 \times 3$ & $\rightarrow$ & $\rightarrow$ & $25 \times 3$ & $\longrightarrow$ & $\rightarrow$ & $\rightarrow$ & $\rightarrow$ & $\longrightarrow$ & $\rightarrow$ & $25 \times 3$ \\
\hline & $25 \times 3$ & $\rightarrow$ & $\longrightarrow$ & $\longrightarrow$ & $25 \times 1$ & $\longrightarrow$ & $\longrightarrow$ & $\longrightarrow$ & $\rightarrow$ & $\rightarrow$ & $25 \times 1$ \\
\hline & & & & & $50 \times 2$ & & & & & & $50 \times 2$ \\
\hline \multirow[t]{2}{*}{52} & $50 \times 3$ & $\rightarrow$ & $\rightarrow$ & $25 \times 3$ & $\rightarrow$ & $\longrightarrow$ & $\rightarrow$ & $\rightarrow$ & $\rightarrow$ & $\rightarrow$ & $25 \times 3$ \\
\hline & $25 \times 3$ & $\rightarrow$ & $\longrightarrow$ & $\rightarrow$ & $\longrightarrow$ & $\longrightarrow$ & $\longrightarrow$ & $\longrightarrow$ & $\rightarrow$ & $\rightarrow$ & $25 \times 3$ \\
\hline 57 & $50 \times 2$ & $\rightarrow$ & $\rightarrow$ & $\longrightarrow$ & $25 \times 3$ & $\rightarrow$ & $\rightarrow$ & $\rightarrow$ & $\rightarrow$ & $\rightarrow$ & $25 \times 3$ \\
\hline \multirow[t]{2}{*}{70} & $50 \times 3$ & $\rightarrow$ & $\rightarrow$ & $\rightarrow$ & $\rightarrow$ & $\rightarrow$ & $\rightarrow$ & $\rightarrow$ & $\longrightarrow$ & $\rightarrow$ & $50 \times 3$ \\
\hline & $50 \times 3$ & $\rightarrow$ & $\longrightarrow$ & $\longrightarrow$ & $\longrightarrow$ & $\longrightarrow$ & $\longrightarrow$ & $\longrightarrow$ & $\longrightarrow$ & $\rightarrow$ & $50 \times 3$ \\
\hline 86 & $50 \times 3$ & $\longrightarrow$ & $\longrightarrow$ & $50 \times 4$ & $\longrightarrow$ & $\longrightarrow$ & $\longrightarrow$ & $\longrightarrow$ & $\longrightarrow$ & $\longrightarrow$ & $50 \times 4$ \\
\hline \multirow[t]{2}{*}{113} & $25 \times 3$ & $\rightarrow$ & $\rightarrow$ & $\rightarrow$ & $\longrightarrow$ & $\rightarrow$ & $\rightarrow$ & $\rightarrow$ & $\rightarrow$ & $\rightarrow$ & $25 \times 3$ \\
\hline & $25 \times 3$ & $\rightarrow$ & $\longrightarrow$ & $\longrightarrow$ & $\longrightarrow$ & $\longrightarrow$ & $\longrightarrow$ & $\longrightarrow$ & $\longrightarrow$ & $\rightarrow$ & $25 \times 3$ \\
\hline 130 & $25 \times 2$ & $\longrightarrow$ & $\longrightarrow$ & $25 \times 3$ & $\longrightarrow$ & $\longrightarrow$ & $\longrightarrow$ & $\longrightarrow$ & $\longrightarrow$ & $\longrightarrow$ & $25 \times 3$ \\
\hline 172 & $50 \times 3$ & $\rightarrow$ & $\rightarrow$ & $\rightarrow$ & $\longrightarrow$ & $\rightarrow$ & $\rightarrow$ & $\rightarrow$ & $\longrightarrow$ & $\rightarrow$ & $50 \times 3$ \\
\hline 173 & $50 \times 3$ & $\rightarrow$ & $\longrightarrow$ & $\longrightarrow$ & $\longrightarrow$ & $\longrightarrow$ & $\longrightarrow$ & $\longrightarrow$ & $\rightarrow$ & $\rightarrow$ & $50 \times 3$ \\
\hline 180 & $50 \times 3$ & $\rightarrow$ & $\rightarrow$ & $\rightarrow$ & $\rightarrow$ & $\longrightarrow$ & $\longrightarrow$ & $\longrightarrow$ & $\rightarrow$ & $\rightarrow$ & $50 \times 3$ \\
\hline 204 & $50 \times 3$ & $\rightarrow$ & $\rightarrow$ & $\rightarrow$ & $\longrightarrow$ & $\rightarrow$ & $\rightarrow$ & $\rightarrow$ & $\rightarrow$ & $\rightarrow$ & $50 \times 3$ \\
\hline 312 & Pen & $\rightarrow$ & $25 \times 3$ & $\longrightarrow$ & $\longrightarrow$ & $\longrightarrow$ & $\longrightarrow$ & $\longrightarrow$ & $50 \times 3$ & $\rightarrow$ & $50 \times 3$ \\
\hline 314 & Pen & $\rightarrow$ & $25 \times 3$ & $\rightarrow$ & $\rightarrow$ & $\rightarrow$ & $\rightarrow$ & $\rightarrow$ & $\rightarrow$ & $\rightarrow$ & $25 \times 3$ \\
\hline
\end{tabular}

while on this dose, although patient 70 , pregnancy 1 , had a urine copper value of 0.139 and 0.182 at months 1 and 7 , respectively. We suspect problems with compliance in this patient because her urine zinc values were $0.9 \mathrm{mg}$ and $2.6 \mathrm{mg}$, respectively.

Table 4 presents data on the preservation of the mother's liver function, and if relevant, neurological function, during pregnancy. Table 4 presents the closest liver and neurological function data available, before and after the pregnancies. Because many of these patients were followed at long distance, the data are not as comprehensive as the urine data, which were usually obtained from mail-in samples. Before and after liver function data were collected on 10 women involving 15 pregnancies, and show stability in the mothers' liver function (Table 4). Neurological and/or speech scores were collected on 3 women who had presented with neurological disease, totaling 5 pregnancies, and again showed functional stability.

Table 5 presents a summary of fetal outcome, with one major (microcephaly) and one minor fetal (surgically correctable heart defect) abnormality among the 26 live births. Average urine copper values during pregnancy, and the patients' rank in urine copper, from highest to lowest, are also shown. We are aware of 4 miscarriages (not reported here).

\section{DISCUSSION}

When choosing or recommending an anticopper therapy for a Wilson's disease patient during pregnancy, a physician must consider both sustaining the health of the mother, and the avoidance of teratogenicity in the fetus. It is clear that anticopper therapy must continue during pregnancy. Patients who have discontinued penicillamine therapy to avoid birth defects in a child have experienced serious remission of Wilson's disease, including death. ${ }^{33-36}$

There is considerable experience with penicillamine treatment during pregnancy, and if taken properly, it appears to sustain the mother's health, and keep her Wilson's disease under control.33,35,36 However, penicillamine is associated with significant teratogenicity in both animals and humans. ${ }^{37-39,42}$ In the human it produces a cutis laxis syndrome, which in its severe form can resemble Ehlers-Danlos syndrome, or produce micrognathia, low set ears, and other abnormalities. Rosa ${ }^{40}$ has concluded that, "the available evidence suggests that a prudent course for conditions for which there are safer alternatives would be to discontinue penicillamine during pregnancy."

With penicillamine falling into some disfavor for use during pregnancy because of its teratogenic effects, there have been some pregnant patients maintained on trientine. Walshe ${ }^{45}$ has reported on 7 patients who were treated with trientine through 11 pregnancies. Eight healthy babies resulted. Regarding the other 3, 1 baby was delivered prematurely and had a chromosomal defect (isochromosome X), there was 1 miscarriage at 14 weeks, and 1 therapeutic abortion. The infants' ceruloplasmin levels were measured and averaged $9.9 \mathrm{mg} / \mathrm{dL}$, not different than controls (mean, 10.0; range, 5.6 to 18.0). However, 2 infants from Wilson's disease mothers did have rather low values of 3.6 and 4.6. The urine copper values in the mothers, both "basal" and after treatment, tended to increase during and immediately after pregnancy, in 2 cases rather markedly. These results were attributed to poor compliance.

There are also single case reports from Spain ${ }^{46}$ and from France. ${ }^{47}$ In the Spanish case, a 22-year-old woman with 
TABLE 4. Liver Function Tests and Quantitative Neurological and Speech Scores Before and After Pregnancy

\begin{tabular}{|c|c|c|c|c|c|c|c|c|c|c|c|}
\hline $\begin{array}{l}\text { Patient } \\
\text { No. }\end{array}$ & $\begin{array}{c}\text { Pregnancy } \\
\text { No. }\end{array}$ & $\begin{array}{l}\text { Date of } \\
\text { Delivery }\end{array}$ & $\begin{array}{l}\text { Date of Liver } \\
\text { Function Tests }\end{array}$ & Bilirubin & Albumin & ALT & AST & $\begin{array}{l}\text { Date of Neurology } \\
\text { Scores }\end{array}$ & $\begin{array}{l}\text { Neurology } \\
\text { Scores }\end{array}$ & $\begin{array}{c}\text { Date of } \\
\text { Speech Scores }\end{array}$ & $\begin{array}{l}\text { Speech } \\
\text { Scores }\end{array}$ \\
\hline \multirow[t]{2}{*}{27} & 1 and 2 & $5 / 94,5 / 96$ & $10 / 93$ & 1.3 & 4.6 & 41 & 38 & & & & \\
\hline & & & $1 / 98$ & 1.1 & 4.6 & 103 & 58 & & & & \\
\hline \multirow{3}{*}{32} & & & $7 / 87$ & 0.5 & 4.1 & 147 & 77 & & & & \\
\hline & 2 & $5 / 90$ & $9 / 88$ & 0.2 & 4.3 & 85 & 51 & & & & \\
\hline & & & $9 / 92$ & 0.5 & 3.9 & 112 & 72 & & & & \\
\hline \multirow[t]{4}{*}{45} & 1 & $8 / 87$ & $10 / 86$ & 0.6 & 4.4 & 26 & 19 & & & & \\
\hline & & & $10 / 87$ & 1.0 & 4.7 & 37 & 33 & & & & \\
\hline & 2 & $6 / 90$ & $10 / 88$ & 0.5 & 4.7 & 21 & 27 & & & & \\
\hline & & & $9 / 90$ & 0.5 & 3.9 & 21 & 21 & & & & \\
\hline \multirow[t]{2}{*}{49} & 1 & $5 / 89$ & $10 / 86$ & 0.3 & 3.8 & 30 & 19 & & & $11 / 86$ & 2 \\
\hline & & & $5 / 90$ & 0.4 & 3.1 & 25 & 15 & & & $5 / 90$ & 2 \\
\hline \multirow[t]{2}{*}{57} & 1 & $7 / 92$ & $11 / 91$ & 1.4 & 4.7 & 31 & 30 & & & & \\
\hline & & & $12 / 92$ & 1.2 & 4.1 & 28 & - & & & & \\
\hline \multirow[t]{2}{*}{70} & 1 & $6 / 91$ & $9 / 89$ & 0.2 & 2.8 & 15 & 24 & & & & \\
\hline & & & $10 / 92$ & 0.3 & 3.3 & - & 33 & & & & \\
\hline \multirow[t]{2}{*}{113} & 1 & $6 / 97$ & $6 / 95$ & 0.5 & - & 36 & 20 & & & & \\
\hline & & & $8 / 97$ & 0.7 & 3.8 & 41 & 26 & & & & \\
\hline \multirow[t]{2}{*}{312} & 1 & $5 / 95$ & $10 / 94$ & 0.2 & 4.5 & - & - & & & & \\
\hline & & & $11 / 97$ & 0.5 & 4.3 & 61 & 31 & & & & \\
\hline
\end{tabular}

Abbreviations: ALT, alanine transaminase; AST, aspartate transaminase.

TABLE 5. Fetal Outcome of Live-Birth Pregnancies in Wilson's Disease

\begin{tabular}{|c|c|c|c|c|}
\hline $\begin{array}{l}\text { Patient } \\
\text { No. }\end{array}$ & $\begin{array}{l}\text { Pregnancy } \\
\text { Number }\end{array}$ & Fetal Outcome & $\begin{array}{l}\text { Average Urine } \\
\text { Copper Values } \\
\text { During Pregnancy } \\
\text { (mg/24 hours) }\end{array}$ & $\begin{array}{c}\text { Urine } \\
\text { Copper Rank } \\
\text { (From Highest } \\
\text { to Lowest) }\end{array}$ \\
\hline \multirow[t]{2}{*}{27} & 1 & Normal Baby & 0.108 & 8 \\
\hline & 2 & Normal Baby & 0.163 & 2 \\
\hline \multirow[t]{2}{*}{32} & 1 & Normal Baby & 0.149 & 3 \\
\hline & 2 & Normal Baby & 0.094 & 9 \\
\hline 34 & 1 & Normal Baby & 0.140 & 4 \\
\hline 38 & 1 & Normal Baby & - & - \\
\hline 41 & 1 & Normal Baby & 0.074 & 16 \\
\hline \multirow[t]{2}{*}{45} & 1 & Normal Baby & 0.093 & 10 \\
\hline & 2 & Normal Baby & 0.070 & 18 \\
\hline \multirow[t]{2}{*}{49} & 1 & Normal Baby & 0.087 & 11 \\
\hline & 2 & Normal Baby & 0.110 & 7 \\
\hline \multirow[t]{2}{*}{52} & 1 & Normal Baby & 0.062 & 19 \\
\hline & 2 & N ormal Baby & 0.084 & 12 \\
\hline 57 & 1 & $\begin{array}{l}\text { Heart defect requiring } \\
\text { surgery at } 6 \text { mo }\end{array}$ & 0.054 & 21 \\
\hline \multirow[t]{2}{*}{70} & 1 & Normal Baby & 0.140 & 5 \\
\hline & 2 & Normal Baby & - & - \\
\hline 86 & 1 & N ormal Baby & 0.045 & 23 \\
\hline \multirow[t]{2}{*}{113} & 1 & $\begin{array}{l}\text { M icrocephalic baby that } \\
\text { died } 1 \text { hour after birth }\end{array}$ & 0.071 & 17 \\
\hline & 2 & Normal Baby & 0.082 & 13 \\
\hline 130 & 1 & Normal Baby & 0.115 & 6 \\
\hline 172 & 1 & Normal Baby & 0.077 & 14 \\
\hline 173 & 1 & Normal Baby & 0.061 & 20 \\
\hline 180 & 1 & Normal Baby & 0.051 & 22 \\
\hline 204 & 1 & Normal Baby & 0.075 & 15 \\
\hline 312 & 1 & Normal Baby & 0.212 & 1 \\
\hline 314 & 1 & Normal Baby & - & - \\
\hline
\end{tabular}

presymptomatic Wilson's disease was treated with trientine $(1.0 \mathrm{~g} / \mathrm{d})$ during her pregnancy. Trial of labor induction at 42 weeks failed, and a cesarean section had to be performed, with delivery of a heal thy baby. Liver function was unchanged in the mother during and after pregnancy. The French case was a 20-year-old pregnant patient who had presented with severe liver disease at age 15 . She had improved nicely on trientine therapy and was continued on this drug $(0.9 \mathrm{~g} / \mathrm{d})$ during pregnancy. A healthy baby was delivered at 42 weeks. Liver function in the mother did not change during pregnancy.

In summary of trientine, it appears to adequately protect the mother's health, and in a limited number of live births (a total of 11), only one major abnormality (isochromosome X) has been reported. However, trientine is teratogenic in animals. ${ }^{41,42}$

We decided to evaluate zinc therapy during pregnancy in Wilson's disease patients, first because our extensive clinical research with zinc in the process of getting it approved by the FDA for maintenance therapy gave us reassurance that it would protect the mother's health, and second, zinc is not teratogenic in animal studies. ${ }^{43}$ Our data here do provide ample evidence that the mother's health is protected by zinc therapy. Although urine copper values occasionally were el evated (Table 2), no adverse effects on liver or neurological function were found (Table 4).

With respect to the fetal outcome, we had 2 congenital defects in a total of 26 live births, a rate of $7.7 \%$ (Table 5 ). The rate for major and minor congenital defects in the population as a whole is about 4\% (data from March of Dimes web site). Whether with larger numbers the rate of defects found in zinc-treated pregnancies will equal the general population, or be higher, remains to be seen. The expected rate for any single 
major defect is quite low, for example, 1 in 8,000 for anencephaly. It is of interest to note that Bumah et al. ${ }^{48}$ have reported that low serum copper concentrations in pregnant women during midgestation is a risk factor for anencephaly. The women in their report were, of course, not Wilson's disease patients, but the concordance with our one case of microcephaly bears watching. Our single case of a specific major defect does not provide a rate, and thus our case of microcephaly should only be noted at this point. If repeated again (prior to several thousand cases) it may become meaningful.

Based on animal studies, there is reasonably good evidence that a major factor in the production of teratogenicity by penicillamine and trientine is copper deficiency in the fetus. ${ }^{49,50}$ It is possible that the major risk of teratogenicity in Wilson's disease pregnancies is overtreatment, reducing the copper level too low in the mother, and thereby affecting the fetus. If so, all anticopper treatments the mother might take could have some risk of teratogenicity, because of the risk of overtreatment. If this reasoning is correct, the physician should perhaps aim for reasonable but not tight control of the mother's copper status during pregnancy. In this connection it is of interest that when we average the 24-hour urine copper values during pregnancy in the 23 patients on whom we have data from in Table 2, the 2 patients whose babies had birth defects (patients 113 and 57) ranked near the bottom (17th and 21st, respectively) in urine copper values (Table 5).

Another factor to consider is the manner in which the drug exerts its anticopper effect. Both penicillamine and trientine are chelators that function by combining with copper and increasing its urinary excretion. Therefore, there is a built in "pulsatile" nature to this therapy. An oral dose is given, and as the drug builds up in the blood stream, it decreases the level of readily available copper because of copper chelation, with the lowest level of available copper being reached as the drug level hits its peak after each dose. These "troughs" in availability of copper in the mother's blood would be expected to be replicated in fetal blood, and if they happen to be low enough, and perhaps occur at critical times in fetal development when a higher level of copper is required, be causative of defects.

Zinc, on the other hand, has a unique mechanism of action among anticopper agents. Zinc acts on the intestinal cell to block absorption of copper. Zinc therapy induces intestinal cell metallothionein, which has a high affinity for copper. Copper coming into the intestinal cell is bound to metallothionein, preventing its serosal transfer. As intestinal cells slough into the lumen of the bowel with about a 6-day turnover time, they take the contained metallothionein-copper complex with them, and the copper is excreted into the stool. This mechanism not only functions with food copper, but with the large amounts of endogenously secreted copper that are part of salivary, gastric, and other gastrointestinal secretions. Thus, the patient is put into a negative copper balance with zinc therapy, and copper stores are gradually depleted. This mechanism would not be expected to produce troughs in blood copper availability, but rather to possibly blunt "peaks" of blood copper after mealtime. This "leveling" of blood copper levels, as opposed to peaks and troughs might be better physiologically for the fetus, and offer at least a theoretical advantage of zinc therapy.

We have recently reported extensive follow-up (up to 10 years) data on 141 Wilson's disease patients treated with zinc alone as maintenance therapy. ${ }^{27}$ The general conclusion of that study was that zinc was a completely effective, nontoxic, treatment for Wilson's disease. The only side effect we have encountered is occasional gastric discomfort. Zinc must be taken away from food to be fully effective, and the zinc acetate capsules are sometimes irritating to the stomach. In such patients we recommend taking the first dose at midmorning rather than on first arising. If problems continue, the troublesome doses can be taken with a small amount of protein, such as lunch meat, cheese, or jello. Protein interferes with zinc action the least of all foods.

In our long follow-up study, we did find that therapy compliance was a problem. ${ }^{27}$ Approximately $10 \%$ of patients exhibited chronic compliance problems, (easily detected by a drop in the urine zinc below expected values), and almost a third of patients had occasional noncompliance episodes. It is likely that some of the elevated urine copper values we observed in this study (Table 2) are also caused by poor compliance.

In terms of dose of zinc to use during pregnancy, our tentative recommendations are to use the standard dose of 50 mg taken 3 times daily $(50 \times 3)$ for patients whose 24 -hour urine copper values generally are over $0.1 \mathrm{mg}$. However, for patients whose 24-hour urine copper values are generally under $0.1 \mathrm{mg}, 25 \mathrm{mg}$ taken 3 times daily $(25 \times 3)$, or even lower doses, might be considered. Obviously, patients' urine copper (and zinc) levels should be monitored during pregnancy, and if the copper values get too high or too low, compliance evaluated and adjustments in zinc dose should be made if necessary. These recommendations are, of course, only tentative until more experience is gained.

In summary, we believe zinc is a reasonable choice for pregnant Wilson's disease patients. It is effective and generally well tolerated. The mother's health is protected during pregnancy. The pregnancy outcome data (Table 4), al though limited, indicate a rate of birth defects of $7.7 \%$, only slightly higher than the general population risk (4\%). Penicillamine is clearly a poor choice for the pregnant Wilson's disease patient because of its relatively high risk of teratogenicity. Limited data on trientine so far have shown 1 major abnormality in 11 live births, a 9\% rate. As more data come in for trientine and for zinc, a clearer picture should emerge as to which (if either) is a superior therapy during pregnancy.

Acknowledgment: The work with zinc therapy was assisted by Gate Pharmaceutical Co., M ontgomeryville, PA. The authors also acknowledge the assistance and support of the Clinical Research Center of the University of Michigan Hospitals.

\section{REFERENCES}

1. Brewer GJ, Yuzbasiyan-Gurkan V. Wilson disease. M edicine 1992;71:139164.

2. Bull PC, Thomas GR, Rommens JM, Forbes JR, Cox DW. The Wilson disease gene is a putative copper transporting P-type ATPase similar to the M enkes gene. $N$ at Genet 1993;5:327-337.

3. Tanzi RE, Petrukhin K, Chernov I, Pellequer JL, Wasco W, Ross B, Parano $E$, et al. The Wilson disease gene is a copper transporting ATPase with homology to the Menkes disease gene. Nat Genet 1993;5:44-50.

4. Yamaguchi Y, Heiny ME, Gitlin JD. Isolation and characterization of a human liver cDNA as a candidate gene for Wilson disease. Biochem Biophy Res Commun 1993;197:271-277.

5. Bush JA, Mahoney JP, Markowitz H, Gubler CI, Cartwright GE, Wintrobe M M. Studies on copper metabolism. XVI. Radioactive copper studies in normal subjects and in patients with hepatolenticular degeneration. J Clin Invest 1955;34:1766-1778. 
6. Frommer DJ. Defective biliary excretion of copper in Wilson's disease. Gut 1974;15:125-129.

7. O'Reilly S, Weber PM, Oswald M, Shipley L. Abnormalities of the physiology of copper in Wilson's disease. III. The excretion of copper. Arch Neurol 1971;25:28-32.

8. Gibbs K, Walshe JM. Biliary excretion of copper in Wilson's disease. Lancet 1980;2:538-539.

9. Iyengaar V, Brewer GJ, Dick RD, Owyang, C. Studies of cholecystokininstimulated biliary secretions reveal a high molecular weight copperbinding substance in normal subjects that is absent in patients with Wilson's disease. J Lab Clin Med 1988;111:267-274.

10. Walshe, JM. Penicillamine. A new oral therapy for Wilson's disease. Am J Med 1956;21:487-495.

11. Walshe JM. Treatment of Wilson's disease with trientine (triethylene tetramine) dihydrochloride. Lancet 1982;1:643-647.

12. Brewer GJ, Hill GM, Prasad AS, Cossack ZT, Rabbani P. Oral zinc therapy for Wilson's disease. Ann Intern Med 1983:99:314-320.

13. Hill GM, Brewer GJ, Prasad AS, Hydrick CR, Hartmann DE. Treatment of Wilson's disease with zinc: I. Oral zinc therapy regimens. HePATOLOGY 1987;7:522-528.

14. Hill GM, Brewer GJ, Juni JE, Prasad AS, Dick RD. Treatment of Wilson's disease with zinc: II. Validation of oral ${ }^{64}$ copper uptake with copper balance. Am J Med Sci 1986;12:344-349,

15. Brewer GJ, Hill GM, Dick RD, N ostrant TT, Sams JS, Wells JJ, Prasad AS Treatment of Wilson's disease with zinc: III. Prevention of reaccumulation of hepatic copper. J Lab Clin Med 1987;109:526-531.

16. Brewer GJ, Hill GM, Prasad AS, Dick RD. Treatment of Wilson's disease with zinc: IV. Efficacy monitoring using urine and plasma copper. Proc Soc Exper Biol Med 1987;7:446-455.

17. Yuzbasiyan-Gurkan V, Brewer GJ, Abrams GD, Main B, Giacherio D. Treatment of Wilson's disease with zinc: V. Changes in serum levels of lipase, amylase and alkaline phosphatase in Wilson's disease patients. J Lab Clin Med 1989;114:520-526.

18. Brewer GJ, Yuzbaysian-Gurkan V, Lee D-Y, Appelmann H. The treatment of Wilson's disease with zinc: VI. Initial treatment studies. J Lab Clin Med 1989;114:633-638.

19. Lee D-Y, Brewer GJ, Wang Y. The treatment of Wilson's disease with zinc: VII. Protection of the liver from copper toxicity by zinc induced metallothionein in a rat model. J Lab Clin Med 1989;114:639-645

20. Brewer GJ, Yuzbasiyan-Gurkan V, Dick R. Zinc therapy of Wilson's disease: VIII. Dose response studies. Trace Elem in Exp Med 1990;3:227234

21. Brewer GJ, Yuzbasiyan-Gurkan V, Johnson V. The treatment of Wilson's disease with zinc: IX. Response of serum lipids. J Lab Clin Med 1991;118:466-470.

22. Yuzbasiyan-Gurkan V, Grider A, N ostrant T, Cousins RJ, Brewer GJ. The treatment of Wilson's disease with zinc: X. Intestinal metallothionein induction. J Lab Clin Med 1992;120:380-386.

23. Brewer GJ, Yuzbasiyan-Gurkan V, Johnson V, Dick RD, Wang $Y$, Treatment of Wilson's disease with zinc: XI. Interaction with other anticopper agents. J Amer Coll Nut 1993;12:26-30.

24. Brewer GJ, Yuzbasiyan-Gurkan V, Johnson V, Dick RD, Wang Y. Treatment of Wilson's disease with zinc: XII. Dose regimen requirements. Amer J Med Sci 1993;305:199-202.

25. Brewer GJ, Dick RD, Yuzbasiyan-Gurkan V, Johnson V, Wang $Y$. Treatment of Wilson's disease with zinc: XIII. Therapy with zinc in presymptomatic patients from the time of diagnosis. J Lab Clin Med 1994:123:849-858.

26. Brewer GJ, Johnson V, Kaplan J. Treatment of Wilson's disease with zinc: XIV. Studies of the effect of zinc on lymphocyte function. J Lab Clin M ed 1997;129:649-652.

27. Brewer GJ, Dick RD, Johnson V, Brunberg JA, Kluin KJ, Fink JK. Treatment of Wilson's disease with zinc: XV. Long-term follow-up studies. J Lab Clin Med 1998;132:264-278.
28. Brewer GJ, Dick RD, Johnson V, Fink JK, Kluin KJ, Daniels S. Treatment of Wilson's disease with zinc: XVI. Treatment during the pediatric years (provisionally accepted, Am J Gastroenterol).

29. Schouwink, G. De hepatocecerebrale degeneratie, met een onderzoek naar de zonkstrofwisseling. MD thesis (with a summary in English, French, and German). University of Amsterdam; 1961.

30. Hoogenraad TU, Koevoet R, De Ruyter Korver EGW M. Oral zinc sulfate as long-term treatment in Wilson's disease (hepatolenticular degeneration). Eur N eurol 1979;18:205-211.

31. Hoogenraad TU, Van den Hamer CJA, Koevoet R, De Ruyter Korver EGW M. Oral zinc in Wilson's disease. Lancet 1978;2:1262-1263.

32. Hoogenraad TU, Van Hattum J, Van den Hamer CJA. Management of Wilson's disease with zinc sulfate. Experience in a series of 27 patients. Neurol Sci 1987;77:137-146.

33. Scheinberg IH, Sternlieb I. Pregnancy in penicillamine-treated patients with Wilson's disease. N Engl J Med 1975;293:1300-1302.

34. Deiss A, Lee GR, Cartwright GE. Hemolytic anemia in Wilson's disease. Ann Intern Med 1970;73:413-418.

35. Maracek Z, Graf M. Pregnancy in penicillamine treated patients with Wilson's disease. N Engl J Med 1976;295:841-842.

36. Scheinberg IH, Sternlieb I. Wilson's Disease. Major Problems in Internal Medicine. Volume 23. Philadel phia: Saunders, 1984.

37. Keen CL, Mark-Savage B, Lönnerdal B, Hurley LS. Teratogenic effects of D-penicillamine in rats: relation to copper deficiency. Drug Nutr Interact 1983;2:17-34.

38. Mjolnerod OK, Dommerud SA, Rasmussen K, Gjeruldsen ST. Congenital connective tissue defect probably due to $\mathrm{D}$-penicillamine treatment in pregnancy. Lancet 1971;1:673-675.

39. Solomon L, Abrams G, Dinner M, Berman L. Neonatal abnormalities associated with D-penicillamine treatment during pregnancy. N Engl J Med 1977;296:54-55.

40. Rosa FW. Teratogen update: Penicillamine. Teratology 1986;33:127-131.

41. Keen CL, Cohen NL, Lönnerdal B, Hurley LS. Teratogenesis and low copper status resulting from triethylenetetramine in rats. PSEBM 1983; 173:598-605.

42. Tanaka H, Yamanouchi M, Imai S, Hayashi Y. Low copper and brain abnormalities in fetus from triethylene tetramine dihydrochloridetreated pregnant mouse. J Nutr Sci Vitaminol 1992;38:545-554.

43. Food and Drug Administration. Teratologic evaluation of FDA 71-49 (zinc sulfate). Food and Drug Research Laboratories, Inc. Prepared for Food and Drug Administration, United States Department of Commerce Publications PD-221 805, February 1973, and PB 267, June 1974.

44. Brewer GJ, Dick RD, Yuzbasiyan-Gurkan V, Tanakow R, Young AB, Kluin $\mathrm{KJ}$. Initial therapy of Wilson's disease patients with tetrathiomolybdate. Arch Neurol 1991;48:42-47.

45. Walshe JM. The management of pregnancy in Wilson's disease treated with trientine. Q J Med, 1986;58:81-87.

46. Devesa R, Alvarez A, de las Heras G, de Miguel JM. Case report: Wilson's disease treated with trientine during pregnancy. J Ped Gastroent Nutr 1995;20:102-103.

47. Desbriere R, Roquelaure B, Sarles J, Boubli L. Grossesse chez une patient traitée par trientine dihydrochloride pour maladie de Wilson. La Presse Médicale 1998;27:806

48. Bumah PH, Russell M, Milford-Ward A, Taylor P, Roberts DF. Serum copper concentrations significantly less in abnormal pregnancies. Clin Chem 1984;30:1667.

49. Cohen NL, Keen CL, Lönnerdal B, Hurley LS. The effect of copper supplementation on the teratogenic effects of triethylenetetramine in rats. Drug Nutr Interact 1983;2:203-210.

50. Keen CL, Lönnerdal B, Hurley LS. Drug-induced copper deficiency: A model for copper deficiency teratogenicity. Teratology 1983;28:155-156. 